\title{
Autoethnography as a method of facilitating critical reflexivity for professional doctorate students
}

\author{
Dr Catherine Hayes \\ University of Sunderland, UK \\ Dr John Anthony Fulton \\ University of Sunderland, UK
}

\section{Abstract}

This paper explores autoethnography within the context of the professional doctorate and argues that it is an excellent way of linking theory to the practical situation. The paper commences by defining the 'second generation' of professional doctorates (Maxwell, 2003) where the focus is directed primarily to work-based learning and the development of work-based practice. Candidates are expected to demonstrate the development of practice and their contribution to this in a fundamentally original approach. The researcher is central in the practical or work-based situation and the process of autoethnography can structure and guide the research process, by providing structure to the process of reflexivity. The paper considers two broad approaches to autoethnography: the traditional approach and the post-modernist approach. The post-modernist approach presents challenges in the ways in which the work is presented: a central argument of the paper is that despite the novel ways of presentation, the work should have a strong theoretical base. The paper concludes by summarising the role of autoethnography in the professional doctorate: autoethnography provides a factually accurate and comprehensive overview of the professional doctorate candidate's career trajectory. It should act as a driver of self-explication for the professional doctorate student thus providing a degree of both catalytic and educative authenticity, and provide an insight for the reader of the professional doctoral thesis.

Keywords: autoethnography; professional doctorate; reflective process. 


\section{Introduction}

The concept of the Professional Doctorate (Prof Doc) has gained momentum in recent years in the UK, and the popularity of this approach to postgraduate research has increased exponentially since the mid-1990s. Maxwell (2003) introduced the term 'second generation' of professional doctorates where the focus was directed primarily to workbased learning and the development of work-based practice; candidates are expected to demonstrate the development of practice and their contribution to this in a fundamentally original approach. It is geared towards (although, not exclusively) the mid-career professional who wishes to develop their practice to doctoral academic level and further develop their professional practice to a level commensurate with the most unique and innovative contribution to their professional discipline (Costley and Lester, 2012). In much the same way as the novice researcher will develop their research skills through the Ph.D., the professional doctorate candidate is expected to submit a portfolio of evidence of this strategic development of professional practice and an associated academic and theoretically underpinned commentary.

In this second generation, Prof Doc students are permitted to begin their project from the development of an entirely new piece of work, which they then wish to develop. One of the challenges here is to provide a methodological framework which unifies and directs their work and allows them to develop in a systematic and rigorous manner. There are a variety of methodological approaches which can be used and this paper will highlight autoethnography. Autoethnography has a clear relevance to vocational learning and the practical skills required to devise a portfolio of evidence, linking prior achievement to current researcher status, and how these act as dynamic drivers of change for professional practice and future career progression. The doctoral candidate needs to demonstrate critical reflection which is associated with the process of practice development.

Within doctoral level study - particularly Doctor of Philosophy programmes - much emphasis has been placed upon the implementation of relatively traditional approaches to question-led research. Autoethnography has, in Professional Doctorates particularly, a legitimacy where contribution to a field of practice can both be articulated and rooted philosophically. This legitimacy stems from the need to move beyond theory which is 
primarily explanatory, to one which can also focus on process and outcome within the context of employment and the recollection of career trajectories.

Many of the Professional Doctorate students encountered in practice conceptualise and produce their stories or accounts of previous experience in the form of a chronological timeline which is marked with focal points of key achievements, critical incidents and major personal life events, which have influenced and shaped their particular career trajectories. It is in this context where autoethnography arguably has greatest significance in facilitating students as they seek to emphasise a deeply personal journey the destination of which is their current position and contribution to practice to date. With their Director of Studies and the critical feedback gained as a result of interaction with them, the student undertakes a process of co-construction of their journey, not necessarily rooted in a process of storytelling but in a directed and recursive narrative of personal and professional achievement. There can be accompanying issues with inter-subjectivity at this point and it is here that a rigorous approach to the use of autoethnography can provide valuable frameworks which transcend the dialogue of the Director of Studies with the Professional Doctorate student. Perhaps one of the greatest issues of contention regarding whether a Doctorate in Philosophy and a Professional Doctorate equate to one another in terms of an evidence base, can be addressed through the use of a method which lifts the student's account of their professional career trajectory from the anecdotal and which places it firmly in the category of a valid methodological framework. Most significantly it roots the person within the context of personal and professional growth and the discourse which accompanies these processes (Barresi and Juckes, 1997; Singer, 2004).

Professional Doctorate students need to provide evidence of their career trajectories through a structured portfolio - this is another incidence of the programme of study where autoethnography encompasses collecting artefacts such as evidence of publications, films and video clip contributions to practice, supporting letters from previous managers, or even reflective logs or memoires. Often triangulation of evidence is executed through the collation of other sources of evidence which corroborates initial claims of professional contribution to an area. This is of particular significance to the scientific rigour of the Professional Doctorate, where issues of trustworthiness and authenticity might be raised as an integral part of educational quality management in the academic assessment process. 
This paper provides an insight into how autoethnography can be used as a qualitative method of facilitating critical reflexivity for students undertaking a programme of study leading to the award of Professional Doctorate. Autoethnography is a therapeutic and reflexive means through which Professional Doctorate students can deliberately and consciously embed themselves within theoretical perspectives and perhaps more significantly the application of these perspectives to practice. Additionally autoethnography can facilitate a critical reflexivity where the candidate can position themselves against the relevant theoretical underpinnings. As students become critically reflexive about their contribution to practice, autoethnography provides a valuable mechanism for developing autobiographical accounts of personal experience, practical interventions and personal perceptions of what their contribution to a professional field of practice actually is.

\section{Autoethnography}

Frayling (1993) in discussing design research discusses research into design, by which he means a theoretical investigation into design; research for design or the production of artefacts and research through design which is concerned with design practice, and the researcher communicates both the process and the product. Although Frayling (1993) was writing about a very specific area of practice, this can be translated to more general practice development issues and it is the development of research though practice which in many ways is the essence of the professional doctorate.

While not using the term research through practice, Costley and Lester (2010) discuss approaches to professional doctorates and suggest that there are three broad approaches which can be taken: some candidates follow a conventional approach and undertake a systematic research study, using 'practice friendly' methodologies such as action research, appropriate to the development of practice. The other extreme are those at the end of their career who pull their work together and demonstrate through evidence and a reflective account their impact on practice. Perhaps more commonly are a group of mid-career professionals who come with a body of work usually comprising a number of studies or innovations and wish to develop the work to the standard of the professional doctorate. What is common to all approaches is that an element of reflection is essential; this reflection draws out the thought processes, ways in which things have changed in expediency, how difficulties and problems are considered. 
The key is perhaps reflection, or reflexivity which is a more accurate term: it is the presence of the researcher in the research process from conception of the idea through to the choice of the methodology, to the impact of the researcher in the setting and the writing up process of the findings. In qualitative research, and particularly in ethnography, it is now seen as an essential part of the research process and in methods such as action research it is actually built into the methodology. One way of ensuring rigour is through autoethnography; autoethnography is a methodological approach which acknowledges the centrality of the researcher in the process of the research and provides an excellent means of structuring the reflection. Autoethnography is an extension of the autoethnographic tradition and the researcher's presence is paramount to the research. The researcher is writing about his or her experience and in doing so makes the process transparent to the reader of the study.

The term autoethnography originates linguistically as a merge of auto-biography and ethnography (Ellis et al., 2011) - the autobiography element is concerned with the self and ethnography with cultures. The ethnographic tradition focuses on the natural world and the researcher studies the world in the natural setting. The usual approach is to enter in the world or go native, whereby the researcher may live with those being studied or at least he or she will spend a significant amount of time in the research setting. The aim is to make the world intelligible and to explain to the reader what is happening and why things are done in a particular manner. The anthropologist Clifford Geertz (1973) called this 'thick description', in which the situating is described in such manner than explanations are also considered. The auto-biographical element presents a greater challenge.

Autoethnography has a long tradition and its central feature is the central position of the researcher - their experiences, feelings and views are a central part of the process of autoethnography. Anderson (2006) outlines the key features of ethnography: the researcher should be part of the area of investigation, he or she should employ a degree of analytical reflexivity, there should be an engagement with the informants, the researcher should be visible in any accounts and should have a commitment to theoretical analysis. Autoethnographers and professional doctorate candidates are certainly part of their setting and their presence is central to the development of practice, whilst 'informant' might not be the most accurate term, they do interact and engage with people in their setting. Analytical reflexivity and a commitment to theoretical analysis are a little more problematic but should, or rather must, be explicit in professional doctorates. 
Butler (2005) discusses the self in relation to knowledge and argues that we are opaque to the self, and any accounts which are concerned with an exploration of self-identity can only really be done by an exploration of the social world. In many ways this is the key to autoethnography. It is the consideration of the self within a socio-cultural context. This is particularly relevant to the professional doctorate where the focus is an exploration of the development of an aspect of practice and the wider aspects of practice are therefore essential. Autoethnography can, therefore, be thought to be about the self in the context of a specific culture, and unlike many ethnographic studies were the research studies a foreign or unfamiliar culture, the autoethnographer is writing about his or her own culture, be it the culture of their work or of their everyday life. In the case of the professional doctorate candidate, they are writing about their workplace and themselves within that particular culture.

There are many similarities and dissimilarities between conventional ethnography and autoethnography. The reflexivity in which the ethnographer considers their position, and the ways in which the research involves him or herself in the research process and the impact this presence can have on the respondents, is fully reported in most ethnographic accounts. It is also central to all autoethnographic reports. The main difference is the centrality of the researcher to the process, they are right there in the centre, shaping and guiding the process. In traditional ethnography, whilst it is recognised that the researcher can influence the process, they tend to be on the side lines looking in, whereas the autoethnographer is central and often is the one directing the process.

\section{Using story and reflection accounting as both data and method}

So while autoethnography can be an appropriate approach in the professional doctorate, and this does bring out the centrality of the experience of the candidate, the decision as to what approach to take is perhaps more difficult. Does the individual candidate go for an approach which makes the theoretical issues and analytic reflexivity transparent? Or does he or she go for an approach which is less conventional and draws on less conventional presentation styles? The first approach can be very easily assessed, the theory and methodology is explicit, and it fits Anderson's criteria. The second approach is much less conventional but can lead to insights and views in a unique and novel manner. 
Since the concept of history and recalled discourse plays such a central role in the development of the portfolio of evidence which students submit as an integral part of their assessment for the award of Professional Doctorate, it is necessary to frame these within an appropriate model for practical application. The three of greatest relevance are the Contextual-Action Theory of Career (Young and Valach, 2004; Young et al., 2002), the Theory of Career Construction (Savickas, 2005) and the Systems Theory Framework (Patton and McMahon, 2006). Autoethnography as a discipline has long been acknowledged as a mechanism of comprehensively articulating elements of critical reflexivity relevant to different contexts and academic disciplines, but the case can be presented for its implementation in a doctoral programme which places value on the priori knowledge of doctoral students and the communities of practice to which they belong and contribute to.

Autoethnography transcends particular disciplines, however central to all disciplinary approaches. Since it permits a true ontological and epistemological background to the generation of emergent theory, the participant can be clearly understood as being socially constructed and in a constant flux regarding their personal image. This is entirely attributable to the person underpinning the professional, which is significant in relation to the development of professional doctorate portfolios of evidence, which are arguably a reflection of the personal as well as the professional.

In essence, autoethnography bridges the gap between theory and practice through the development of a critical discourse and the reflexivity which develops as a natural consequence of it. Narrative and storytelling can be regarded as being equivalent since both contribute to this discourse in terms of their contribution to the autoethnography of the student. In terms of underpinning ontological and epistemological approaches, it permits a clear acknowledgement of the essence of being a person and being a professional, which is a valuable addition to the student's academic course of study and their own personal progression and transferable skill development as a reflexive practitioner.

Positioning autoethnography as a trustworthy and authentic means of reflexive enquiry necessitates a consideration of the notion of personhood. Personhood transcends the professional doctorate student's professional identity, regardless of where that might be situated, and permits their identity to be in the person rather than the professional. It is in the person that thoughts, feelings and value judgements can be legitimised and 
rationalised in terms of the personal decision making and critical introspection which often necessarily underpins professional practice. Ultimately it can define and frame the person and not just their professional identity.

The development of critical consciousness which permits the professional doctorate student to be a systematic and logical constructor of narrative discourse has been the focus of debate in educational disciplines for several years. The theoretical framework supporting and guiding the processes of reflection, praxis, and subsequently autoethnography, ultimately underpin the notion of reflexivity. Whether professional doctorate students need training in the development of critical consciousness remains an issue in curriculum development and curriculum justification across professional doctorate programmes.

\section{Approaches to autoethnography}

The idea of post modernism is central to the development of autoethnographical approaches. This is not to say that autoethnography and post modernism are synonymous, although many autoethnographic accounts sit firmly within this tradition. Post-modernism is notoriously difficult to define, but one prominent feature of postmodernism is the lack of grand narrative (Lyotard, 1984), that is, there is no explanation at the macro level. What is of concern is a consideration of people's stories and their experience and the ways in which particular realities are constructed. Another key characteristic is the mixture of genres, as is evident in architecture, films and literature, very different styles are mixed in an eclectic and often haphazard manner. The thinking of Foucault is particularly relevant and his idea of discourses is central. Discourses are concerned with the ways in which people, things and concepts are represented in the written and the verbal form: they both reflect and shape how people think (Georgakopoulou and Goutsos, 2004).

The justification for use of autoethnography in pedagogic practice calls for an identification of what the core characteristics of narrative enquiry actually are. Hoshmand (2005) defined three distinct types of reporting accounts of practice that fit with the narrative approach adopted for Professional Doctorate students, which distinguishes the nature of their 
educational journey as different but equal to students undertaking more traditional Doctorate of Philosophy programmes:

a) A purely descriptive write up of a reflective diary in its original form.

b) An account in the form of extended narrative which gives an account of personal and professional experience which is made up of interview transcripts, written reports, observational fieldwork and anecdotal evidence or artefacts.

c) A recounting of dialogue which has been generated in the form of narratives in essentially a storytelling fashion.

One of the major challenges in autoethnography is how to capture the essence of the self within a cultural context; at the risk of oversimplifying things there are two broad approaches which can be taken which can be entitled the traditional approach (equating with $\mathrm{a}$ and $\mathrm{b}$ ) and the post-modernist approach (equating with $\mathrm{c}$ ). The traditional approach is along very similar lines as a conventional ethnographic study, and the post-modernist approach allows for a mixture of styles and focuses very much on the expression and the medium of communication to convey the experience.

Two examples of the conventional approach are defined by Chang (2008) and Duncan (2004). Chang (2008) outlines an approach in which whilst there is a consideration of individual experience, it examines the individual experience against a culture or subculture, and how that culture has influenced the individual and how the individual has been influenced by that culture. It has perhaps a greater focus on auto-biography than ethnographic accounts but follows a conventional recognisable approach. Duncan (2004) outlines a slightly different take on autoethnography in which the research is focused on the individual's practice, and is usually fairly specific, or a specific project. The research collects data in much the same way as in (conventional) qualitative research studies; data is collected in a systematic manner and is analysed, which allows themes to emerge which are then discussed.

The 'evocative' approach is more controversial and is by no means universally accepted. Here the expression is central, and less conventional styles (and mediums) than the traditional academic styles are employed. It is perhaps typified by its key exponents (Ellis and Bochner, 2000), and it is sometimes called evocative autoethnography (Anderson, 2006), where the idea is to write in such a way that emotions are evoked in the reader. 
The researcher reflects on, and writes an account of, an area of experience and considers their experience in some detail. Less conventional research approaches are followed and data is presented in a variety of ways; through poetry, painting, or more commonly a story, an account written with high literary quality in which the message is more important than the literal truth. This is not to say that the research is falsified but the findings or the issues are more important than what literary happened. An example of this is in Ellis' (2004) 'The autoethnographic l' (subtitled an autoethnographic novel) whereby she makes up a character representing at least two people and saying the type of things commonly said in the particular setting. Sparkes (2007) also writes in this tradition and he writes a semiautobiographical account of the day in the life of an academic in a narrative or story form. In his account there are no explicit theoretical concerns and the reader is left to relate it to broader theoretical concerns for themselves.

However, MacLure (2006) compares post-modernist approaches in research to art and links them to the surreal and baroque styles, maintaining that these rather off beat styles can give rise to many insights. To continue the comparison with art, the first approach (as typified by Chang (2008) and Duncan (2004)) is similar to conventional painting in which the artist seeks to represent a particular scene in a recognisable manner, people familiar with say the landscape could recognise it easily. The second approach (as typified by Ellis and Sparkes) is like an abstract painter who is expressing him or herself and attempting to engage the viewer to evoke an emotional response. The viewer might not fully understand it but engages at some level with the picture. In the case of autoethnography many valuable insights can be gained through this process. Focusing on the second approach it raises the question that what then is the difference than say autoethnographic accounts? Indeed many valuable insights can be gained from accounts of people's experiences of a particular situation or experience. Ellis and Bochner (2000) consider breast cancer within an autoethnographic account, and while this work does provide some insights, so it can be argued do more standard autobiographical accounts.

To return to Anderson's criteria for ethnography (Anderson, 2006) and the importance of analytical reflexivity and a commitment to theoretical analysis, these are less evident in autoethnography, and certainly in the post-modernist accounts. Maclure (2006), while not writing explicitly about autoethnography, discusses post-modernist approaches to educational research and, whilst far from conventional, provides many insights which could not be gained from more traditional forms of research. To return to the metaphor of 
painting, the abstract painter is trained in conventional methods and uses these techniques in his or her work. Similarly the autoethnographer is classically trained (so to speak) and uses these techniques, and whilst accounts may not explicitly discuss theoretical issues, it is implicit in their work and the reader can therefore engage at different levels.

What is also significant is the role of the reader in autoethnography, since it is the reader who establishes the inherent value of the narrative in terms of assessing its underpinning theoretical basis, and the potential transferability of concepts from the narrative to their own area of expertise. For the purposes of autoethnography in the Professional Doctorate pathways this can be termed transgressive validity (Ellis and Bochner, 2000).

\section{Aligning the philosophical basis of autoethnography with the professional doctorate programme}

The professional doctorate would certainly encourage students to develop a conceptual framework within which they can best express their personal realities through the power of written and, in the case of the Viva Voce examination, verbal discourse. The student would philosophically assume 'personal reality' to be a psychosocial construction, with a correspondingly expected degree of emphasis placed upon internal issues, the context and external factors involved, and the degree of personal agency evident between the social constructionism and constructivism divide. It could even be suggested that autoethnography sits epistemologically within the context of phenomenology, since authors of both seek to demonstrate transparency in presenting discourse which reveals personal experience. In terms of transparency, autoethnography provides the Professional Doctorate students with a means of expressing their embedded stance as researchers of their own personal journey. It also provides a mechanism of ensuring that its axiology has a clear conceptual origin. In terms of rhetorical structure, autoethnography varies widely, which is another significant reason for incorporating it as an integral part of a Professional Doctorate programme. This degree of rhetoric cannot be unravelled from method since the approach adopted necessitates a degree of rhetorical expression in how it is reported and further developed. 
In summary, the central role of autoethnography in the professional doctorate ought to:

a) Provide a factually accurate and comprehensive overview of the professional doctorate student's career trajectory, which encompasses ontological authenticity and meaningfulness.

b) Act as a driver of self-explication for the professional doctorate student, thus providing a degree of both catalytic and educative authenticity.

c) Provide an insight for the reader of the professional doctoral thesis, which describes phenomena they might never have before experienced or might never anticipate experiencing again in the future, or perhaps where a sense of meaningfulness in sharing the experience with others from the same community of practice has not yet happened.

\section{Conclusion}

Whilst autoethnography has been presented in this article as a virtual panacea for the development of extended discourse, which informs the reader of the critical consciousness of the professional doctorate student, it still nevertheless has limitations which need to be acknowledged. It is certainly not universally accepted. Wacquant (2014), for example, warns us against the 'glamorous seductions of post-modernist story telling'. Autoethnography is by no means universally accepted in academic circles, with Holt (2003) providing an interesting account of the difficulties of getting autoethnographical accounts published in the academic press. In common with any other autoethnographic accounts of personal and professional experience, there are no guarantees in inspiring interest in the reader of the professional doctoral thesis. In this it is important to differentiate between the concept of the 'knower' and the 'potential knower'. Acknowledging limits in 'self-knowing' is an issue of much contention (Wilson and Dunn, 2004), but the nature of all qualitative research means that it only has context specificity at the particular point in time of the experience being reported upon. This means that the ability to generalise from the narrative account of experience is either claimed or alluded to, and that in terms of assessing scientific rigour and quality, in comparison to empirically based Doctorate of Philosophy programmes, is not an issue. In the context of professional doctorate programmes, autoethnography is a methodological tool which permits a critical understanding for professionals from a whole array of working contexts and environments 
to illuminate a critical view of their own selves, and to bring a degree of intellectual objectivity into what can then become a shared interdisciplinary perspective.

\section{References}

Anderson, L. (2006) 'Analytic autoethnography', Journal of Contemporary Ethnography, 35(4), pp. 373-395.

Barresi, J. and Juckes, T.J. (1997) 'Personology and the narrative interpretation of lives', Journal of Personality, 65(3), pp. 693-719.

Butler, J. (2005) Giving an account of oneself. New York: Fordham University Press.

Chang, H. (2008) Autoethnography as method. Walnut Creek, CA: Left Coast Press.

Costley, C. and Lester, S. (2012) 'Work-based doctorates: professional extension at the highest levels', Studies in Higher Education, 37(3), pp. 257-269.

Duncan, M. (2004) 'Autoethnography: critical appreciation of an emerging art', International Journal of Qualitative Methods, 3(4), pp. 1-4.

Ellis, C. (2004) The ethnographic I: a methodological novel about autoethnography. CA: Rowman Altamira.

Ellis, C. and Bochner, A.P. (2000) 'Autoethnography, personal narrative, reflexivity: researcher as subject', in Denzin, N.K. and Lincoln, Y.S. (eds.) The handbook of qualitative research. 2nd edn. Newbury Park, CA: Sage, pp. 733-768.

Ellis, C., Adams, T. and Bochner, A.P. (2011) 'Autoethnography: an overview', Forum Qualitative Sozialforschung, Forum: Qualitative Social Research, 12(1) [Online]. Available at: http://www.qualitative- research.net/index.php/fqs/ article/view/ 1589/3 096 (Accessed: 14 January 2015).

Frayling, C. (1993) Research in art and design. London: Royal College of Art. 
Geertz, C. (1973) 'Thick description: toward an interpretive theory of culture', in Geertz, C. (ed.) The interpretation of cultures: selected essays. New York: Basic Books, pp. 330.

Georgakopoulou, A. and Goutsos, D. (2004) Discourse analysis: an introduction. Edinburgh: Edinburgh University Press.

Holt, N.L. (2003) 'Representation, legitimation, and autoethnography: an autoethnographic writing story', International Journal of Qualitative Methods, 2(1), pp. 1-21.

Hoshmand, L.T. (2005) 'Narratology, cultural psychology, and counselling research', Journal of Counseling Psychology, 52(2), pp. 178-186.

Lyotard, J.F. (1984) The postmodern condition: a report on knowledge, Vol. 10. Minnesota: University of Minnesota Press.

MacLure, M. (2006) 'A demented form of the familiar': postmodernism and educational research', Journal of Philosophy of Education, 40(2), pp. 223-239.

Maxwell, T. (2003) 'From first to second generation professional doctorate', Studies in Higher Education, 28(3), pp. 279-291.

Patton, W. and McMahon, M. (2006) Career development and systems theory: connecting theory and practice. Rotterdam: Sense Publishers.

Savickas, M. (2005) 'The theory and practice of career construction', in Brown, S.D. and Lent, R.W. (eds.) Career development and counseling: putting theory and research to work. Hoboken, NJ: John Wiley and Sons, pp. 42-70.

Singer, J.A. (2004) 'Narrative identity and meaning making across the adult lifespan: an introduction', Journal of Personality, 72(3), pp. 437-459.

Sparkes, A.C. (2007) 'Embodiment, academics, and the audit culture: a story seeking consideration', Qualitative Research, 7(4), pp. 521-550. 
Wacquant, L. (2014) 'Für eine Soziologie aus Fleisch und Blut. SublUrban', Zeitschrift FüR Kritische Stadtforschung, 2(3), pp. 93-106. Available at: http://zeitschriftsuburban.de/sys/index.php/suburban/article/view/151/252 (Accessed: 19 January 2015).

Wilson, T.D. and Dunn, E.W. (2004) 'Self-knowledge: its limits, value and potential for improvement', Annual Review of Psychology, 55(1), pp. 493-518.

Young, R.A. and Valach, L. (2004) 'The construction of career through goal-directed action', Journal of Vocational Behavior, 64(3), pp. 499-514.

Young, R.A., Valach, L. and Collin, A. (2002) 'A contextualist explanation of career', in Brown, D.A. (ed.) Career choice and development. 4th edn. San Francisco, CA: Jossey-Bass, pp. 206-252.

\section{Author details}

Dr Catherine Hayes is Principal Lecturer in the Faculty of Applied Sciences, Department of Pharmacy Health and Wellbeing, University of Sunderland.

Dr John Anthony Fulton is Principal Lecturer in the Faculty of Applied Sciences, Department of Pharmacy Health and Wellbeing, University of Sunderland. 